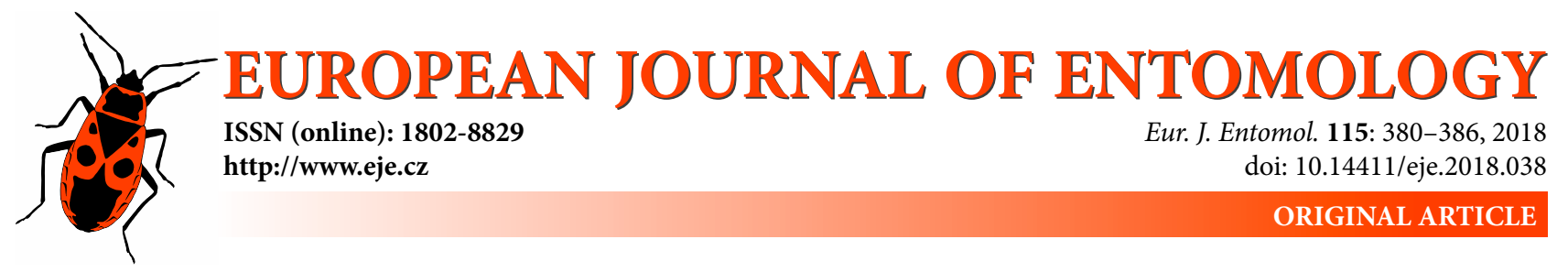

\title{
Feeding behaviour of young larvae of Pieris rapae crucivora (Lepidoptera: Pieridae) and its effect on parasitism by Cotesia glomerata (Hymenoptera: Braconidae)
}

\author{
Aya NAKAYAMA, KeIJI NAKAMURA* and Jun TAGAWA \\ Department of Biosphere-Geosphere System Science, Faculty of Informatics, Okayama University of Science, Ridai-cho 1-1, \\ Okayama 700-0005, Japan; e-mails: aya.glomerata@gmail.com, nakamura@big.ous.ac.jp, cotesiagl@gmail.com
}

Key words. Lepidoptera, Pieridae, Pieris rapae crucivora, cabbageworm, Hymenoptera, Braconidae, Cotesia glomerata, attraction, avoidance, distance, escape, feeding mark, feeding site, host searching, larva, move, parasitism, parasitoid, rest

\begin{abstract}
We investigated the effect of the feeding behaviour of young larvae of Pieris rapae crucivora Boisduval (Pieridae) on parasitism by the parasitoid wasp, Cotesia glomerata (L.) (Braconidae). Young, 1st-3rd instar larvae used approximately three sites for feeding each day. When not feeding, they moved a short distance away from the feeding sites (= feeding marks) and rested. For first, second and third instar larvae, the distances from the new mark, made within $24 \mathrm{~h}$, to larva at rest were, respectively, about $3.5 \mathrm{~mm}, 5 \mathrm{~mm}$ and more than $10 \mathrm{~mm}$. To resume feeding, they moved back to one of the former feeding sites or a new site. The percentage of the feeding marks older than $24 \mathrm{~h}$ that attracted parasitoids was less than $50 \%$. Time spent searching for hosts by a parasitoid was short. Larvae placed $5 \mathrm{~mm}$ or more from a feeding mark were less parasitized than the larvae placed near a mark. The number of feeding marks affected parasitism. When comparing single-marked and triple-marked leaves, the percentage parasitism of the larvae on the latter was significantly lower than that of the larvae on the former. On triple-marked leaves, parasitoids visited each mark unevenly. Accordingly, the time spent searching each mark differed significantly among the marks. Because of this confusing effect, hosts are considered to be reducing the risk of parasitism. Our results demonstrate that the feeding habits of young larvae of $P$. rapae crucivora are adaptive in terms of reducing the risk of parasitism by $C$. glomerata.
\end{abstract}

\section{INTRODUCTION}

Many insects have evolved various types of defensive behaviour to counter attacks by parasitoids. Parasitism success is influenced directly by host behaviour (Gerling et al., 1990; Gross, 1993; Völkl \& Stadler, 1996; Firlej et al., 2010). For example, grooming behaviour in the cricket Gryllus texensis (Gryllidae) is regarded as a defensive mechanism against the parasitoid fly Ormia ochracea (Tachinidae) as it results in the offspring of this parasitoid deposited on the host body surface being removed (Vincent \& Bertram, 2010). Forest tent caterpillars, Malacosoma disstria (Lasiocampidae), reduce the risk of parasitism as a group by flicking their heads and biting (McClure \& Despland, 2011). For the leaf miner Ophiomyia maura (Agromyzidae), the percentage parasitism of larvae that excavate complicated tracks in leaves is lower than that of larvae excavating simple tracks (Ayabe \& Ueno, 2012), thereby indicating a relation between the feeding behaviour of hosts and parasitism.

Pieris rapae crucivora Boisduval (Lepidoptera: Pieridae) is a well-known, small white butterfly in Japan. The larvae, called cabbageworms, feed mainly on cabbage and to some degree on radish and other cruciferous plants in open sunny fields (Ohsaki \& Sato, 1999). Cabbageworms are affected by predation and parasitism by many natural enemies, such as spiders, bugs, paper wasps, parasitoid flies and wasps, and birds. It is likely that large larvae are at a greater risk of being attacked by predators than small larvae. Small larvae are more likely to be vulnerable to parasitoids than large larvae (Slansky, 1986; Van Driesche, 1988; Reavey, 1993). The gregarious parasitoid wasp Cotesia glomerata (L.) (Hymenoptera: Braconidae) attacks young Pieris larvae and strongly affects the population dynamics of $P$. rapae crucivora (Matsuzawa, 1958; Ohsaki \& Sato, 1990). Percentage parasitism of $P$. rapae crucivora by $C$. glomerata are high in Japan. Some investigations report that more than $80 \%$ of the larvae are parasitized (Matsuzawa, 1958; Ohsaki \& Sato, 1990, 1994, 1999). It is therefore likely that cabbageworms have evolved methods for reducing the risk of parasitism.

Young adult females of $P$. rapae crucivora fly long distances from their emergence sites (Ohsaki, 1980). This be-

\footnotetext{
* Corresponding author; e-mail: nakamura@big.ous.ac.jp
} 
haviour functions as a mechanism of parasitoid-avoidance (Ohsaki \& Sato, 1990). Nevertheless, it is also preferable for young larvae to be able to reduce the incidence of parasitism. When attacked by the parasitoid, $P$. rapae crucivora larvae seem to resist being parasitized by thrashing their bodies. It sometimes spits saliva at the attacking wasp. However, these offensive behaviours are useless if performed by early instar larvae, which are the principal hosts of $C$. glomerata (Matsuzawa, 1958). In fact, these larvae have no countermeasures: the resistance behaviour of young larvae has little effect on parasitoids. Tagawa et al. (2008) report that young, 1st-3rd instar larvae of $P$. rapae crucivora tend to stay on the lower surface of leaves. This behaviour acts as a parasitoid-avoidance mechanism because the percentage parasitism of larvae on the lower surface is less than that of larvae on the upper surface of leaves (Tagawa et al., 2008).

Cotesia glomerata females seek hosts on and near feeding marks on leaves by detecting cues such as chemical substances synthesized by the tissues around the wounds caused by the larvae of their host (Sato, 1979; Horikoshi et al., 1997). Therefore, the feeding behaviour of hosts must be important for host-parasitoid relationships, as shown for leaf miners (Ayabe \& Ueno, 2012). Nevertheless, feeding behaviour of cabbageworms has not been investigated from this point of view.

This study was designed to elucidate whether the feeding behaviour of young $P$. rapae crucivora larvae affects parasitism by $C$. glomerata. We first investigated the feeding patterns of the host and then parasitism of the hosts was examined in relation to their position to the feeding marks on a leaf.

\section{MATERIALS AND METHODS}

\section{Host}

Eggs, larvae and adult butterflies of Pieris rapae crucivora Boisduval were collected from fields in Okayama, Japan, during 2010 and 2012. Eggs were allowed to hatch in the laboratory at room temperature. Newly hatched larvae and larvae collected in the field were reared in $350 \mathrm{ml}$ plastic cups with absorbent paper on the underside of the lids at room temperature on cabbage (Brassica oleracea var. capitata) and horseradish (Armoracia rusticana) until pupation or parasitoid egression. After pupation, the pupae were put in a butterfly cage $(1 \times \mathrm{w} \times \mathrm{h}=130 \times 49 \times$ $136 \mathrm{~cm}$ ) kept in a room. Adult butterflies that emerged from these pupae were fed a dilute solution of honey.

\section{Parasitoid}

Parasitoids were obtained from parasitized larvae of $P$. rapae crucivora collected in the field. Within a day after egression from hosts, the cocoon clusters of Cotesia glomerata (L.) were put in $30 \mathrm{ml}$ glass vials and kept at $20^{\circ} \mathrm{C}$ under a $16 \mathrm{~L}: 8 \mathrm{D}$ photoperiod. To assure mating after adult emergence, both sexes were kept together in the vials for more than 3 days with a drop of honey and water. Then females were allowed to parasitize young $P$. rapae crucivora larvae. These artificially parasitized hosts were reared under the conditions described above.

\section{Observation of host feeding behaviour}

Throughout the experiment, horseradish leaves were used as food for the host larvae. Leaves of approx. 20-30 cm long were collected from the field in May, 2011. Each leaf was copied on a $1 \mathrm{~mm}$ graph paper after washing carefully. Then the leaves were inserted individually into $30 \mathrm{ml}$ glass vials filled with water. Vials were placed in the butterfly cage for a day to collect new eggs. The leaves were then withdrawn from the cage on the following day. For each leaf, only one or two eggs, which were more than $15 \mathrm{~cm}$ apart, were left intact. Other eggs were removed using a fine brush. Eleven leaves were used to determine the feeding habits of the larvae. The locations of all eggs on leaves were marked on the paper copies and numbered. The feeding habits of 17 larvae were recorded until the third moult.

The experimental leaves to which host eggs were attached were kept isolated in the laboratory at room temperature. After hatching, the following items were checked or measured 2-4 times a day, between 10:00-18:00: i.e., instar of each larva, number of feeding marks (scars and/or holes), area of leaf consumed at each feeding mark, and distances between the larva and each mark. When a new feeding mark appeared at the time of observation, the distance between the new mark and the previous mark was measured. Interval between the successive observations was more than $2 \mathrm{~h}$. Each measurement was made using the paper copies of the leaves after accurately recording on them the location of larvae and feeding marks. Feeding marks were numbered successively from the first. When two or more new marks were recorded at an observation, the nearest mark to the larva was regarded as the last one. The furthest mark was regarded as the oldest. When two or more marks merged into one, the earliest number was adopted thereafter for this merged mark. Distance between a larva at rest and the nearest edge of a feeding mark was measured using a digital calliper (Digimatic Caliper; Mitutoyo Corp., Kawasaki, Japan). The minimum distance between the edges of feeding marks was measured similarly. When a larva was feeding when observed, the measurement was postponed until the larva rested.

\section{Attraction of feeding mark for parasitoid}

Fresh, uninjured horseradish leaves of approx. 20-30 cm long were collected from a field in July, 2011. The leaves were washed carefully immediately after collection. To avoid withering, the petiole of each leaf was wrapped in wet cotton wool. To make a single feeding mark, the leaf was covered with a paper towelling with a $5 \mathrm{~mm}$ hole. Then one host larva was placed in the paper hole and covered with a $6 \mathrm{~cm}$ plastic dish. Parasitoids respond to the feeding marks of late instars as well as to those of early instars (Horikoshi et al., 1997). Therefore, a fourth or fifth instar larva was used in this experiment to make a feeding mark. When a roughly $2 \mathrm{~mm}$ wide mark was made, the larva was removed. This procedure was replicated four times from 12:00-15:00 in order to prepare four test leaves.

Each treated leaf was placed horizontally in a transparent plastic case $(15 \times 20 \times 12 \mathrm{~cm}) 6 \mathrm{~cm}$ above the bottom, on which a mirror was placed to facilitate observations. A mated, naive, 9-10-day-old female of C. glomerata was then put on the upper surface of the leaf, $1 \mathrm{~cm}$ from the feeding mark. After covering the case with a transparent acrylic board, the host-searching behaviour of the wasp was observed for 2 min or until it ceased searching. The time to start searching, the time spent searching the upper surface and the time spent searching the lower surface were recorded. Here, antennal touching of the surface of the leaf was regarded as searching for a host (Sato, 1979). Walking away from a mark, walking without antennal touching and the beginning of body cleaning were regarded as indices of the end of searching. When a wasp did not begin searching within $2 \mathrm{~min}$, it was regarded as not responding.

To determine the decline in the attractiveness of feeding marks, observations were recorded after 10-20 min, $2 \mathrm{~h}, 24 \mathrm{~h}, 48 \mathrm{~h}$ and 
$72 \mathrm{~h}$. The numbers of wasps tested for each of the four treated leaves were 4-7. Accordingly, 19-24 wasps were observed for each time condition. The treated leaves were kept carefully in the laboratory during tests for $72 \mathrm{~h}$.

\section{Resting distance of host and parasitism}

To determine the effect of resting distance (i.e., distance from feeding-mark to host at rest) on parasitism, the following experiments were conducted. Fresh, uninjured horseradish leaves approx. $20 \mathrm{~cm}$ long were collected from the field in autumn, 2010. The leaves were washed carefully immediately after collection. The petiole of each leaf was wrapped in wet cotton wool. Then the test leaves, each of which had a single mark, were prepared using the procedure described above. Within $4 \mathrm{~h}$ after the feeding mark was made, a single second instar larva was attached to the lower surface of the leaf using adhesive tape at a certain distance from the mark. Distances were $0 \mathrm{~mm}, 2.5 \mathrm{~mm}, 5 \mathrm{~mm}$ and $10 \mathrm{~mm}$ from the edge of the mark. Each treated leaf was placed horizontally in a transparent plastic case $(15 \times 20 \times 12 \mathrm{~cm}) 6 \mathrm{~cm}$ above the bottom, on which there was a mirror. A mated, naive, 3-14-dayold female of $C$. glomerata was then put on the upper surface of the leaf, at $5-10 \mathrm{~mm}$ distance from the feeding mark. Similar conditioned wasps were used in the following experiments. Host searching behaviour and the degree of host acceptance were the same for young and old females (prelim. obs.). After covering the case with a transparent acrylic board, the host-searching behaviour of the wasp was observed at room temperature until parasitism occurred or the wasp gave up searching. When a wasp did not begin searching within $2 \mathrm{~min}$, it was regarded as not responding. This procedure was replicated 17-20 times for each condition.

In this experiment, the time spent searching the upper and lower surfaces was recorded. Then the parasitism success (recorded as host finding and stinging) or failure (host not found) was confirmed.

\section{Number of feeding marks and parasitism}

To determine the effects of the number of feeding marks on parasitism, we compared leaves with one feeding mark and leaves with three feeding marks. Fresh, uninjured horseradish leaves of approx. $20 \mathrm{~cm}$ long were collected from the field in autumn of 2012. The leaves were washed carefully immediately after collection. The petiole of each leaf was wrapped in wet cotton wool. Leaves with feeding marks were prepared as follows: (1) one 3-mm-wide hole was made in paper towelling; and (2) three holes of the same size were made in paper towelling in a ' $\mathrm{L}$ ' shape, with the end holes $5 \mathrm{~mm}$ from the corner hole. A leaf was covered with one of these papers and marked leaves of two types were prepared using the procedure described above.

Within $4 \mathrm{~h}$ of the feeding marks being produced, a single second instar larva was attached to the lower surface of the leaf using adhesive tape, at a distance of $5 \mathrm{~mm}$ from the mark. The searching behaviour of the parasitoid was observed using the procedure described above. For triple-marked leaves, a wasp was placed opposite the corner mark (assuming a square). Observations were repeated 27 times for single-marked leaves and 32 times for triple-marked leaves, each time using a new leaf and a new wasp.

\section{Host-searching behaviour of $C$. glomerata on triple- marked leaves}

Fresh, uninjured horseradish leaves of approx. $20 \mathrm{~cm}$ length were collected from the field in December, 2012. The leaves were washed carefully immediately after collection. The petiole of each leaf was wrapped in wet cotton wool. Leaves with three feeding marks were prepared. The wasp was placed using the procedure described above. Then the searching behaviour of the parasitoid was observed for $2 \mathrm{~min}$ in the absence of a host larva. The order in which the parasitoid visited each mark and the time spent searching each mark were recorded. This was replicated 20 times.

\section{Statistical analyses}

The number of feeding marks made by hosts, areas of the feeding marks, distances between feeding marks and distances from resting hosts to feeding marks were compared among instars using Kruskal-Wallis test. Multiple comparisons were performed using Dunn's procedure. Time spent searching feeding marks of different ages and for host larvae at different resting distances were compared using Kruskal-Wallis test. Then multiple comparisons were performed using Dunn's procedure. Attractiveness of feeding marks for parasitoids and percentage parasitism of larvae at different distances were compared using a $x^{2}$-test. Correlation between the search time and resting distance of the host was calculated. Time spent searching the upper and lower surfaces, search times associated with parasitism and failure to parasitize, and time spent searching single-marked and triple-marked leaves were evaluated using Mann-Whitney U-tests. The numbers of visits to each feeding mark on triple-marked leaves and time spent searching each mark were evaluated using Kruskal-Wallis tests. Then multiple comparisons were performed using Dunn's procedure.

\section{RESULTS}

\section{Feeding behaviour of host}

The larvae of $P$. rapae crucivora moulted to the third instar 5-6 days after hatching when kept at room temperature. Young larvae were observed to use several sites for feeding. When they were not feeding, they moved a short distance away from feeding sites, or feeding marks, and rested. To resume feeding, they moved back to one of the former feeding sites or a new site.

Table 1 presents some of the characteristics of feeding marks produced by $1 \mathrm{st}-3 \mathrm{rd}$ instar larvae. Numbers of feeding marks made by first, second and third instar larvae were, on average, ca. 4, 7 and 9, respectively, showing an increasing tendency $(p<0.05)$. Mean area of the feeding marks produced by first, second and third larvae increased, respectively, from less than $2 \mathrm{~mm}^{2}$ to ca. $5 \mathrm{~mm}^{2}$ and more than $10 \mathrm{~mm}^{2}(p<0.05)$. Distance to a fresh mark from the previous mark increased with larval development, although not significantly between the second and third instar larvae. Distances from a larva at rest to the nearest edge of a feeding mark (resting distances) for first, second and third instar larvae were, respectively, ca. $5 \mathrm{~mm}, 8 \mathrm{~mm}$ and $16 \mathrm{~mm}$. Resting distances increased significantly with larval development $(p<0.05)$.

To determine the daily activity of larvae, new feeding marks that were made within $24 \mathrm{~h}$ were selected. The numbers of these new marks made by first, second and third instar larva were, respectively, about three (Table 1). In other words, larvae used about three sites for feeding in a day, irrespective of instars (ns). Resting distances from these marks were somewhat shorter than those from all marks, and showed a similar tendency to increase with larval growth $(p<0.05)$. In this study, some larvae moved long distances (several centimetres) from feeding or resting sites, before resting or resuming feeding, but such cases were rare. 
Table 1. Number of feeding marks made by young larvae of Pieris rapae crucivora on leaves of Armoracia rusticana, area of each feeding mark, distance between a fresh feeding mark and the previous feeding mark, and distance from feeding mark to larva at rest.

\begin{tabular}{|c|c|c|c|c|c|c|c|c|}
\hline Larval instar & $n$ & $\begin{array}{l}\text { Number of feeding } \\
\text { marks (mean } \pm \text { SD) }\end{array}$ & $n$ & $\begin{array}{c}\text { Area / mark } \\
\left(\text { mean } \pm \mathrm{SD}, \mathrm{mm}^{2}\right)\end{array}$ & $n$ & $\begin{array}{l}\text { Distance between the latest two } \\
\text { feeding marks (mean } \pm \mathrm{SD}, \mathrm{mm} \text { ) }\end{array}$ & $n$ & $\begin{array}{l}\text { Distance from feeding mark to } \\
\text { larva at rest (mean } \pm S D, m m)\end{array}$ \\
\hline $1 \mathrm{st}$ & 87 & $\begin{array}{c}4.2 \pm 2.1^{\mathrm{a}} \\
{\left[3.2 \pm 1.4^{\mathrm{a}}\right]}\end{array}$ & 364 & $1.8 \pm 1.9^{a}$ & 79 & $3.8 \pm 3.0^{a}$ & $\begin{array}{c}364 \\
{[275]}\end{array}$ & $\begin{array}{l}4.9 \pm 5.4^{\mathrm{a}} \\
{\left[3.5 \pm 3.8^{\mathrm{a}}\right]}\end{array}$ \\
\hline 2nd & 46 & $\begin{array}{l}7.2 \pm 2.3^{\mathrm{b}} \\
{\left[3.3^{\mathrm{a}} \pm 1.2^{\mathrm{a}}\right]}\end{array}$ & 329 & $5.4 \pm 5.6^{b}$ & 39 & $6.6 \pm 5.7^{b}$ & $\begin{array}{c}329 \\
{[154]}\end{array}$ & $\begin{array}{l}8.3 \pm 7.6^{\mathrm{b}} \\
{\left[5.2 \pm 5.6^{\mathrm{b}}\right]}\end{array}$ \\
\hline $3 r d$ & 50 & $\begin{array}{c}9.3 \pm 2.7^{\mathrm{c}} \\
{\left[3.3 \pm 1.3^{\mathrm{a}}\right]}\end{array}$ & 464 & $11.3 \pm 16.0^{c}$ & 37 & $11.2 \pm 16.5^{b}$ & $\begin{array}{c}464 \\
{[166]}\end{array}$ & $\begin{array}{c}15.9 \pm 14.8^{c} \\
{\left[11.5 \pm 12.8^{c}\right]}\end{array}$ \\
\hline
\end{tabular}

Within each column, values followed by different letters are significantly different $(p<0.05$, Dunn's procedure). Figures in brackets are for feeding marks made within $24 \mathrm{~h}$.

\section{Attractiveness of feeding marks for parasitoids}

Feeding marks made by host larvae are attractive for C. glomerata, but the attractiveness changed over time $(p$ $<0.001, x^{2}=20.87$ ). Table 2 presents the percentages of parasitoids attracted to feeding marks of different ages and the time parasitoids spent searching. Almost all parasitoids $(95 \%, 18 / 19)$ were attracted to fresh marks (10-20 mins old). The attraction of feeding marks, or scars, decreased gradually over time, and fell to one-third (7/21) at $72 \mathrm{~h}$. Marks that are $24 \mathrm{~h}$ old attracted more than half $(15 / 24)$ of the parasitoids. For the parasitoids that responded, the time to the start of searching did not differ significantly for the different aged marks. Many wasps responded within a few seconds, although a few wasps took longer to respond. In this study, most searching by parasitoids involved touching the edge of a mark with one antenna. Therefore, the area searched was very close to a feeding mark: almost always within a few millimetres of the mark.

Time spent searching a feeding mark depended significantly on its age $(p<0.01)$, with the time spent searching a mark made $48 \mathrm{~h}$ previously less than $10 \mathrm{~s}$ and one made $72 \mathrm{~h}$ previously significantly shorter than one made within $2 \mathrm{~h}(p<0.05)$. Feeding marks that were made within $24 \mathrm{~h}$ elicited intense search activity in parasitoids. Time spent searching the upper surface and the time spent searching the lower surface of leaves did not differ significantly in any time condition, although the time spent searching the lower surface of marked leaves was longer for $24 \mathrm{~h}$ - and 48 h-old marks. In addition, nearly one-third (21/65) of the wasps did not search the lower surface.

\section{Resting distance of host and parasitism}

Table 3 presents percentage parasitism by C. glomerata of second instar larvae, placed on the lower surface of a leaf of $A$. rusticana at different distances from feeding marks (resting distances of larvae). For resting distances of $0 \mathrm{~mm}, 2.5 \mathrm{~mm}, 5 \mathrm{~mm}$ and $10 \mathrm{~mm}$, the respective percentages of parasitism of larvae were $65 \%(11 / 17), 50 \%$ $(10 / 20), 41 \%$ (7/17) and 45\% (9/20). The percentage parasitism decreased to less than $50 \%$ when larvae were $5 \mathrm{~mm}$ or more from a mark. However, differences recorded at the different distances were not significant $\left(x^{2}=2.20\right)$.

The time spent searching was not significantly correlated with the distances of the resting places of larvae from marks, irrespective of the success or failure in parasitizing a larva (ns; success, $r=0.26$; failure, $r=-0.07$ ). Distance of resting site from feeding marks did not affect the time spent searching. Therefore, four conditions were grouped into one. After pooling the search times (mean \pm SD) of wasps that succeeded and failed to parasitize larvae, it resulted, respectively, in $33.0 \pm 31.6 \mathrm{~s}(n=37)$ and $45.5 \pm$ $28.7 \mathrm{~s}(n=37)$, with the latter longer than the former $(p<$ 0.01 , U-test).

Of the 74 parasitoids used that were released on the upper surface of leaves, 25 individuals (34\%) ceased searching without visiting the lower surface. For the parasitoids that visited the lower surface, the effect of the resting distance was clear. Hosts resting at distances of $0 \mathrm{~mm}$ and $2.5 \mathrm{~mm}$ from marks were all parasitized (11/11 and 10/10, respectively). For resting distances of $5 \mathrm{~mm}$ and $10 \mathrm{~mm}$, the percentages parasitism of the hosts were 64\% (7/11) and 53\% $(9 / 17)$, respectively. When the distance conditions were grouped in two $(0-2.5 \mathrm{~mm}$ and $5-10 \mathrm{~mm})$, the percentages parasitism were significantly different $\left(p<0.001, x^{2}\right.$ $=11.92$ ).

\section{Number of feeding marks and parasitism}

Host larvae fed at three different sites each day. Effect of the number of feeding marks on percentage parasitism

Table 2. Attractiveness of the feeding marks of $P$. rapae crucivora on leaves of $A$. rusticana. Percentage of the parasitoid Cotesia glomerata that were attracted when put $1 \mathrm{~cm}$ from a feeding mark and the time spent searching the upper and lower surfaces of leaves at different times after the leaves were marked (2 min obs.).

\begin{tabular}{|c|c|c|c|c|c|c|c|c|}
\hline \multirow{2}{*}{$\begin{array}{l}\text { Time from when } \\
\text { the leaves were marked }\end{array}$} & \multirow[b]{2}{*}{$n$} & \multirow{2}{*}{$\begin{array}{c}\% \text { of parasitoids } \\
\text { attracted }\end{array}$} & \multirow{2}{*}{$\begin{array}{l}\text { Time to onset of } \\
\text { searching (mean } \pm \mathrm{SD}, \mathrm{s})\end{array}$} & \multicolumn{4}{|c|}{ Time spent searching (mean \pm SD, s) } & \multirow{2}{*}{$\begin{array}{l}\text { Total time spent searching } \\
(\text { mean } \pm S D, s)\end{array}$} \\
\hline & & & & $n$ & upper surface & $n$ & lower surface & \\
\hline $10-20 \mathrm{~min}$ & 19 & 95 & $5.4 \pm 7.6^{\mathrm{a}}$ & 18 & $12.2 \pm 8.6^{a}$ & 11 & $8.8 \pm 5.1^{\mathrm{ab}}$ & $17.6 \pm 9.7^{a}$ \\
\hline $2 \mathrm{~h}$ & 21 & 76 & $10.6 \pm 23.1^{a}$ & 16 & $10.6 \pm 9.0^{a}$ & 11 & $10.5 \pm 7.0^{\mathrm{ab}}$ & $17.9 \pm 10.4^{\mathrm{a}}$ \\
\hline $24 \mathrm{~h}$ & 24 & 63 & $8.4 \pm 21.6^{a}$ & 15 & $6.7 \pm 6.1^{\mathrm{ab}}$ & 9 & $14.0 \pm 9.0^{a}$ & $15.1 \pm 12.4$ ab \\
\hline $48 \mathrm{~h}$ & 21 & 43 & $8.9 \pm 13.2^{a}$ & 9 & $2.0 \pm 1.5^{b}$ & 9 & $5.4 \pm 2.4^{\mathrm{ab}}$ & $7.4 \pm 1.8$ ab \\
\hline $72 \mathrm{~h}$ & 21 & 33 & $1.9 \pm 0.7^{a}$ & 7 & $4.9 \pm 4.3^{a b}$ & 4 & $2.8 \pm 1.5^{b}$ & $6.4 \pm 4.3^{b}$ \\
\hline
\end{tabular}

Within each column, values followed by the same letter are not significantly different $(p>0.05$, Dunn's procedure). 


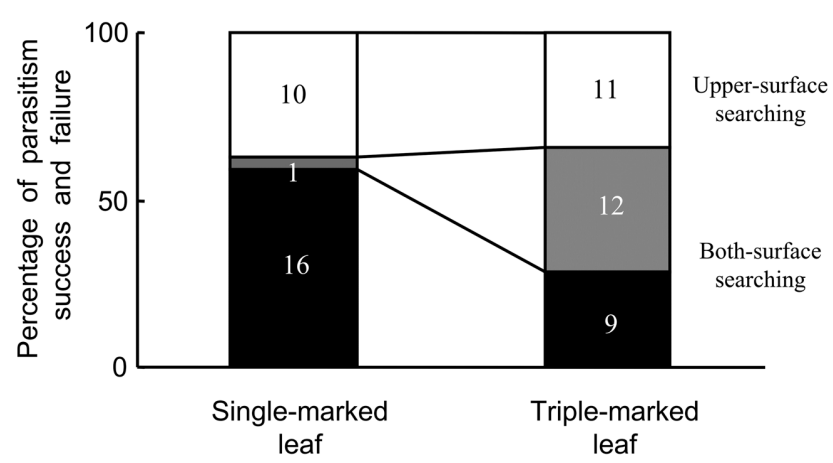

Fig. 1. Percentage of parasitism success and failure of C. glomerata on second instar larvae of Pieris rapae crucivora, placed on the lower surface of $A$. rusticana leaves $5 \mathrm{~mm}$ from the feeding mark on single-marked leaves $(n=27)$ and triple-marked leaves ( = 32): black - success; grey - failure (in both-surface searching) white - failure (in upper-surface searching only); (2 min obs.). The parasitoids were put on the upper surface of the leaves. Figure attached to each bar indicates the number of wasps observed. The percentages parasitism differ significantly $\left(p<0.01, x^{2}=5.81\right)$.

is presented in Fig. 1. On single-marked leaves, the percentage parasitism by C. glomerata of second instar larvae, which were placed on the lower surface $5 \mathrm{~mm}$ from a mark, was $59 \%(16 / 27)$. On triple-marked leaves, the percentage was $28 \%(9 / 32)$, and $38 \%(12 / 32)$ of wasps failed to find hosts when they searched the lower surface. Percentages parasitism of hosts on single-marked and triple-marked leaves differed significantly $\left(p<0.01, x^{2}=5.81\right)$. Time spent searching single- and triple-marked leaves were, respectively, $32.0 \pm 15.2 \mathrm{~s}(n=27)$ and $31.6 \pm 15.5 \mathrm{~s}(n=32)$, which did not differ significantly (U-test).

Of the wasps that searched both surfaces, more than half $(12 / 21)$ of those on triple-marked leaves failed to find hosts. On single-marked leaves, the number of wasps that failed was only one out of 17 , which was very different ( $p$ $\left.<0.001, x^{2}=10.97\right)$. On the single-marked and the triplemarked leaves, the respective percentages of wasps that did not search the lower surface were $37 \%(10 / 27)$ and $34 \%(11 / 32)\left(\mathrm{ns}, x^{2}=0.05\right)$.

\section{Host-searching behaviour of C. glomerata on triple- marked leaves}

On triple-marked leaves, more than half of the parasitoids $(55 \%, 11 / 20)$ searched all three feeding marks. Ten percent $(2 / 20)$ of the parasitoids searched only one mark and the rest $(35 \%, 7 / 20)$ searched two marks. Number (mean $\pm \mathrm{SD}$ ) of movements between marks was $2.7 \pm 2.1$ $(n=20)$, with eight movements as the extreme case. The lo- cations of the three marks did not affect the order in which they were visited by the parasitoid (ns, $x^{2}=0.10$ ). Table 4 presents the number of visits by a parasitoid to each feeding mark, arranged in the order the marks were visited. The number of visits to each mark differed according to when they were visited $(p<0.01)$. The first mark was visited significantly more frequently than the third mark $(p<0.01)$. Time spent searching at each visit was approximately 7-9 $\mathrm{s}$ and not dependent on the order of the visit.

Sometimes one of the three feeding marks on a leaf was visited frequently and at other times not at all. The marks differed in the number of visits. Therefore, time spent searching the different marks is expected to differ even though the time spent searching at each visit was nearly the same. Thus, total time spent searching each of the three marks were not the same $(p<0.05)$. The time spent searching the first mark was, on average, ca. $14 \mathrm{~s}$ and the time spent searching the third mark was ca. 6 s., which differed significantly $(p<0.05)$.

In many cases $(31 / 60)$, the parasitoids visited each mark only once. In 13 out of 60 cases the marks were visited twice and 5 out of 60 more than twice. Nearly one-fifth $(11 / 60)$ of the marks were not visited. The marks that were visited many times were searched for longer. The times spent searching the once-visited marks, twice-visited marks, and those visited more than twice, were, respectively, $8.1 \pm 4.0 \mathrm{~s}(n=31), 14.0 \pm 5.2 \mathrm{~s}(n=13)$ and 26.6 $\pm 24.1 \mathrm{~s}(n=5)$. The time spent searching the once-visited marks was significantly shorter than that spent searching marks that were visited twice or more $(p<0.05)$.

\section{DISCUSSION}

Our observations reveal that young larvae of $P$. rapae crucivora feed at several sites on a single leaf. These sites were close to one another. Distances between feeding sites, or feeding marks, are a few to several millimetres in the case of first and second instar larvae and $10 \mathrm{~mm}$ or more for third instar larvae. When not feeding, young larvae rest a short distance from their feeding sites (Table 1). When they resume feeding, they move to a former feeding site or a new site. They rarely resume feeding at the resting site. The distance from a feeding mark to a larva at rest, or resting distance, was similar to the distance between the marks. Because larvae can rest at feeding sites, movement to the resting sites must be costly for the larvae, even if the resting site is close by. Why do larvae move a short distance away from their feeding site to rest and why do they have several feeding sites?

Table 3. Parasitism by C. glomerata of $P$. rapae crucivora larvae (2nd instar), placed on the lower surface at different distances from feeding marks. The parasitoid was put on the upper surface (2 min obs.).

\begin{tabular}{|c|c|c|c|c|c|c|c|c|}
\hline \multirow{2}{*}{$\begin{array}{l}\text { Distance from } \\
\text { feeding mark }\end{array}$} & \multirow{2}{*}{$n$} & \multirow{2}{*}{$\begin{array}{l}\text { Number of wasps that } \\
\text { searched the lower surface }\end{array}$} & \multirow{2}{*}{\multicolumn{2}{|c|}{$\%$ parasitism $^{1}$}} & \multicolumn{4}{|c|}{ Time spent searching (mean $\pm \mathrm{SD}, \mathrm{s})$} \\
\hline & & & & & $n$ & Success & $n$ & Failure \\
\hline $0 \mathrm{~mm}$ & 17 & 11 & 65 & [100] & 11 & $34.5 \pm 41.8^{a b}$ & 6 & $36.2 \pm 24.5^{a b}$ \\
\hline $2.5 \mathrm{~mm}$ & 20 & 10 & 50 & {$[100]$} & 10 & $21.5 \pm 16.4^{a}$ & 10 & $62.0 \pm 21.8^{a}$ \\
\hline $5 \mathrm{~mm}$ & 17 & 11 & 41 & {$[64]$} & 7 & $20.1 \pm 5.2^{\mathrm{ab}}$ & 10 & $37.3 \pm 40.0^{b}$ \\
\hline $10 \mathrm{~mm}$ & 20 & 17 & 45 & [53] & 9 & $54.0 \pm 34.1^{b}$ & 11 & $43.2 \pm 19.7^{\mathrm{ab}}$ \\
\hline
\end{tabular}

${ }^{1}$ Figures in brackets are percentage success of the wasps that searched the lower-surface. Within each column, values followed by the same letter are not significantly different ( $p>0.05$, Dunn's procedure). 
Table 4. Number of visits to each feeding mark and time spent searching by C. glomerata on triple-marked leaves of $A$. rusticana (2 min obs.)

\begin{tabular}{|c|c|c|c|c|c|}
\hline $\begin{array}{l}\text { Order in which the marks } \\
\text { were visited }\end{array}$ & $n$ & $\begin{array}{l}\text { Number of visits } \\
\text { (mean } \pm S D)\end{array}$ & $n$ & $\begin{array}{l}\text { Time spent searching / visit } \\
(\text { mean } \pm S D, s)\end{array}$ & $\begin{array}{l}\text { Total time spent searching } \\
\qquad(\text { mean } \pm S D, s)\end{array}$ \\
\hline First & 20 & $1.7 \pm 0.9^{a}$ & 33 & $8.5 \pm 7.3^{a}$ & $14.0 \pm 14.6^{a}$ \\
\hline Second & 20 & $1.3 \pm 0.8 \mathrm{ab}$ & 26 & $6.8 \pm 3.4^{a}$ & $8.8 \pm 5.2^{a b}$ \\
\hline Third & 20 & $0.7 \pm 0.7 \mathrm{~b}$ & 14 & $8.0 \pm 3.4^{a}$ & $5.6 \pm 5.8^{b}$ \\
\hline
\end{tabular}

Within each column, values followed by the same letter are not significantly different $(p>0.05$, Dunn's procedure).

When a larva feeds at a certain site on a leaf, it creates a feeding mark or scar. The mark made by larvae of $P$. rapae crucivora is attractive for the parasitoid wasp, C. glomerata (Sato, 1979). Chemical substances synthesized by the tissues around the wounds caused by larvae are the source of the attractant (Horikoshi et al., 1997). The wounds dry out if not fed on continuously or frequently by larvae. Therefore, the attractiveness of feeding marks for the parasitoid depends on how long ago they were made (Table 2 ), with feeding marks older than $24 \mathrm{~h}$ less than half as attractive as freshly made marks and parasitoids spend much less time searching the area. In contrast, the area close to young marks $(<24 \mathrm{~h})$ are highly vulnerable sites for host larvae. For another host-parasitoid relationship, Hanyu et al. (2009) report that the feeding mark made by the northern armyworm, Mythimna separata, is attractive for the parasitoid fly, Exorista japonica. The attractiveness of this mark decreases over a similar period of time, as observed in the present study.

A parasitoid begins searching for hosts by touching the surface of a leaf with its antennae. At the edge of a feeding mark, it rubs its antennae vigorously against the mark and continues searching with its antenna touching the mark. Thus, in most cases, the area searched is very close to the feeding mark. Larvae are expected to reduce the risk of being found by parasitoids if they do not rest close to a feeding mark. In fact, the percentage parasitism of larvae at $5 \mathrm{~mm}$ or a greater distance from feeding marks was low (Table 3). The resting distances of second and third instar larvae are, on average, greater than $5 \mathrm{~mm}$ (Table 1). This 5 mm distance might be crucially important for host-searching parasitoid, as pointed out by Sato (1979). Host larvae are regarded as reducing the risk of parasitism by resting at short distances from feeding marks. This indicates that host larvae at rest do not abandon feeding sites but usually temporarily move away from their feeding marks. Resting at much greater distances is likely to be safer for hosts, but this would involve spending more time moving between feeding and resting sites, which could be costly. Thus, the location of the resting site is thought to be determined by a trade-off between the cost and benefit. In a few cases, larvae move long distances, several centimetres or more, from feeding to resting sites or vice versa, but they did not move back to the former sites. Therefore, this long movement is possibly associated with searching for better and softer food tissues.

Host larvae use approximately three sites, not one site, for feeding during a day. When considering only feeding, having several feeding sites seems costly and inefficient.
When a larva starts feeding at a fresh site, it first scrapes the epidermis of leaf before feeding on the leaf tissue. It might be beneficial for hosts to use former feeding sites, where leaf tissues are already exposed. Moreover, host larvae might be at greater risk of being parasitized by having more than one feeding site, if the time spent searching increases with the number of feeding marks. However, the time spent searching for hosts was unaffected by the number of feeding marks as it was not significantly different on single- and triple-marked leaves. This parasitoid seems to devote a certain amount time to searching for hosts at a particular location. Accordingly, when a parasitoid searches several marks, the time spent searching each mark should decrease. On triple-marked leaves, the time spent searching each mark was less than half of that on single-marked leaves. In addition, the chance that a certain mark will being visited by a parasitoid is not the same for all marks (Table 4). Because of the confusing effects of multiple marks, hosts possibly reduce the risk of being found by parasitoids. In fact, the percentage parasitism of hosts on triple-marked leaves was significantly lower than that of those on single-marked leaves (Fig. 1). Thus, host larvae with several, not one, feeding marks are less likely to be parasitized.

In general, countermeasures against parasitoids are divisible into offensive behaviour and escape behaviour (Gross, 1993). The former includes swinging of the head, spitting of saliva, biting, etc. (Cornell et al., 1987; Gross, 1993; Godfray, 1994; Potting et al., 1999; Gentry \& Dyer, 2002). The latter includes walking away, wriggling, dropping, etc. (Stamp, 1984; Cornell et al., 1987; Gross, 1993; Godfray, 1994; Gentry \& Dyer, 2002). For P. rapae crucivora, offensive behaviour by young larvae is useless. Therefore, they are expected to use escape behaviour.

To date, two measures for avoiding parasitoids are reported for $P$. rapae crucivora. One for adults, in that butterflies move far away from where they emerged and oviposit on parasitoid-free food plants (Ohsaki \& Sato, 1990), and the other is that of their larvae. Young larvae of $P$. rapae crucivora prefer the lower surfaces of leaves. This lower surface preference functions as a parasitoidavoidance mechanism. The percentage parasitism of hosts on the lower surface of leaves is lower than that of those on the upper surface (Tagawa et al., 2008). Host larvae on the lower surface can reduce the risk of being found by $C$. glomerata, because host-searching parasitoids land on the upper surface of leaves (Sato, 1979) and many wasps do not search the lower surface (Tables 2, 3; Fig. 1). Furthermore, frass, a parasitoid-attracting cue (Sato, 1979), drops 
easily from leaves. The present study indicates that larvae have two other ways of avoiding being parasitized: resting a certain distance from feeding marks that attract parasitoid wasps; and having several feeding sites, which confuses the parasitoid.

It is clearly demonstrated that hosts can simultaneously use several parasitoid-avoidance measures. Each of the three measures adopted by young larvae of $P$. rapae crucivora reduces the risk of being found by the parasitoid. Our results indicate that weak hosts, which have no effective resistance measures against parasitoids, have several other measures for avoiding being parasitized. Whether such complex measures for avoiding being parasitized exist in other host-parasitoid relationships requires further careful studies.

ACKNOWLEDGEMENTS. We thank members of our laboratory for their encouragement.

\section{REFERENCES}

Ayabe Y. \& Ueno T. 2012: Complex feeding tracks of the sessile herbivorous insect Ophiomyia maura as a function of the defense against insect parasitoids. — PLoS ONE 7(2): e32594, $8 \mathrm{pp}$.

Cornell J.C., Stamp N.E. \& Bowers M.D. 1987: Developmental change in aggregation, defense and escape behavior of buckmoth caterpillars, Hemileuca lucina (Saturniidae). - Behav. Ecol. Sociobiol. 20: 383-388.

Firlej A., Lucas É., Coderre D. \& Boivin G. 2010: Impact of host behavioral defenses on parasitization efficacy of a larval and adult parasitoid. - BioControl 55: 339-348.

Gentry G.L. \& DYer L.A. 2002: On the conditional nature of neotropical caterpillar defenses against their natural enemies. - Ecology 83: 3108-3119.

Gerling D., Roitberg B.D. \& Mackauer M. 1990: Instar-specific defense of the pea aphid, Acyrthosiphon pisum: Influence on oviposition success of the parasite Aphelinus asychis (Hymenoptera: Aphelinidae). - J. Insect Behav. 3: 501-514.

Godfray H.C.J. 1994: Parasitoids: Behavioral and Evolutionary Ecology. Princeton University Press, Princeton, NJ, 473 pp.

Gross P. 1993: Insect behavioral and morphological defenses against parasitoids. - Annu. Rev. Entomol. 38: 251-273.

HaNYU K., Ichiki R.T., NAKamura S. \& KaINOH Y. 2009: Duration and location of attraction to herbivore-damaged plants in the tachinid parasitoid Exorista japonica. - Appl. Entomol. Zool. 44: $371-378$.

Horikoshi M., Takabayashi J., Yano S., Yamaoka R., Ohsaki N. \& SAто Y. 1997: Cotesia glomerata female wasps use fatty acids from plant-herbivore complex in host searching. $-J$. Chem. Ecol. 23: 1505-1515.
Matsuzawa H. 1958: Ecological studies on the braconid wasp, Apanteles glomeratus. - Mem. Fac. Agr. Kagawa Univ. 3: 1-125 [in Japanese with English abstr.].

McClure M. \& Despland E. 2011: Defensive responses by a social caterpillar are tailored to different predators and change with larval instar and group size. - Naturwissenschaften 98: 425-434.

Ohsaki N. 1980: Comparative population studies of three Pieris butterflies, $P$. rapae, $P$. melete and $P$. napi, living in the same area. II. Utilization of patchy habitats by adults through migratory and non-migratory movements. - Res. Popul. Ecol. 22: 163-183.

OhsAKi N. \& SATo Y. 1990: Avoidance mechanisms of three Pieris butterfly species against the parasitoid wasp Apanteles glomeratus. - Ecol. Entomol. 15: 169-176.

Ohsaki N. \& Sato Y. 1994: Food plant choice of Pieris butterflies as a trade-off between parasitoid avoidance and quality of plants. - Ecology 75: 59-68.

OHSAKi N. \& SATO Y. 1999: The role of parasitoids in evolution of habitat and larval food plant preference by three Pieris butterflies. - Res. Popul. Ecol. 41: 107-119.

Potting R.P.J., Vermeulen N.E. \& Conlong D.E. 1999: Active defence of herbivorous hosts against parasitism: Adult parasitoid mortality risk involved in attacking a concealed stemboring host. - Entomol. Exp. Appl. 91: 143-148.

REAVEY D. 1993: Why body size matters to caterpillars. In Stamp N.E. \& Casey T.M. (eds): Caterpillars: Ecological and Evolutionary Constraints on Foraging. Chapman and Hall, New York, pp. 248-279.

SAто Y. 1979: Experimental studies on parasitization by Apanteles glomeratus. IV. Factors leading a female to the host. Physiol. Entomol. 4: 63-70.

SLANSKY F. JR 1986: Nutritional ecology of endoparasitic insects and their hosts: An overview. - J. Insect Physiol. 32: 255-261.

STAMP N.E. 1984: Interactions of parasitoids and checkerspot caterpillars Euphydryas spp. (Nymphalidae). - J. Res. Lepidop. 23: $2-18$.

Tagawa J., Matsushita A. \& Watanabe T. 2008: Leaf surface preference in the cabbage worm, Pieris rapae crucivora, and parasitism by the gregarious parasitoid Cotesia glomerata. Entomol. Exp. Appl. 129: 37-43.

VAN DRIESCHE R.G. 1988: Field measurement of population recruitment of Apanteles glomeratus (L.) (Hymenoptera: Braconidae), a parasitoid of Pieris rapae (L.) (Lepidoptera: Pieridae), and factors influencing adult parasitoid foraging success in kale. - Bull. Entomol. Res. 78: 199-208.

Vincent C.M. \& Bertram S.M. 2010: Crickets groom to avoid lethal parasitoids. - Anim. Behav. 79: 51-56.

VöLKL W. \& StadLeR B. 1996: Colony orientation and successful defence behaviour in the conifer aphid, Schizolachnus pineti. - Entomol. Exp. Appl. 78: 197-200.

Received November 19, 2017; revised and accepted June 19, 2018 Published online August 14, 2018 